\title{
Analysis of Characteristics of Safety Accidents in University Laboratory and Research on the Causes of Accidents
}

\author{
Kong Shengli ${ }^{1}$, Yang Pengfei ${ }^{1}$, Fang Xinmei ${ }^{1}$, Yang Zhen ${ }^{1}$, Tang Chenlu ${ }^{1}$, Wang Wei ${ }^{2}$ and Ying Chengjing $^{3, *}$ \\ ${ }^{1}$ School of Urban Construction and Safety Engineering, Shanghai Institute of Technology, Shanghai 201418, China \\ ${ }^{2}$ Shanghai Fire Science and Technology Research Institute of MEM, Shanghai 200032, China \\ ${ }^{3}$ Huai'an Modern Tram Operation Co.,Ltd, Huai'an 223000, China
}

\begin{abstract}
In recent years, under the background of the country's vigorous development of science and education, the construction of university laboratories has been continuously progressing and perfecting. Under such rapid development, the safety management mode of university laboratories has been lagging behind and many safety accidents have occurred threatening teachers and students. The safety of university laboratories urgently needs more attention. This research briefly analyzes the safety management system of domestic and foreign university laboratories and related laws, regulations and standards and analyzes the types and characteristics of accidents and the causes of accidents through statistics of 50 college laboratory accidents in recent years. Based on the analytic hierarchy process to study the weight of the cause of the accident. It is concluded that laboratory safety management and personnel management are the main reasons for the accident.
\end{abstract}

\section{Introduction}

In recent years, as the country vigorously develops scientific and technological innovation, university laboratories, as an important place for scientific research, teaching, experimental research and engineering training, have developed rapidly. However, the rapid development of university laboratories also brings some safety problems, mainly in the storage and storage of chemicals in the laboratory, the management of laboratory equipment and the daily laboratory safety inspections. Due to the wide scope of the laboratory, the large number of participants and the large amount of experimental teaching tasks. There are many types of hazardous chemicals with different characteristics in the laboratory. If they are not classified and stored correctly, they will become a potential safety risk. At present, the state has formulated relevant laws and regulations to regulate the management of hazardous chemicals in university laboratories, but lacks requirements for the identification and storage knowledge of chemicals in laboratories ${ }^{[1,2]}$.

Aiming at the safety problems of university laboratories, Hao Longshuai ${ }^{[3]}$, Qi Yue ${ }^{[4]}$, Ma Guojie ${ }^{[5]}$, Liu Liyan ${ }^{[6]}$ etc. conducted detailed analysis on the safety of university laboratories and found that universities have problems with laboratories. The safety management work is not in place, the rules and regulations are not perfect, the organization is not sound, the safety awareness is not strong, the safety management personnel in the laboratory are weak and the hazardous chemicals and waste are improperly handled.

A considerable number of domestic universities pay more and more attention to laboratory management.
Taking Zhejiang University as an example, it involves science, technology, agriculture, medicine and other disciplines. Many laboratories use various dangerous chemicals. Especially those experiments that require special environments and conditions such as high temperature and high pressure, low temperature, radiation and high voltage have caused a series of safety and environmental protection, such as the safety management of hazardous chemicals, the implementation of laboratory rules and regulations and laboratory sewage (three wastes) Question ${ }^{[7]}$. Laboratory safety management has become the most basic and critical link in the development of Chinese universities ${ }^{[8]}$. Reputable universities such as the Hong Kong Polytechnic University offer compulsory education and non-compulsory safety courses. Students must undergo safety training before entering the laboratory and can enter the laboratory after passing the exam. Mainland universities have gradually realized the importance of laboratory safety management. Some schools implement the laboratory safety access system mainly through training courses, in-school publicity and media education. It plays an active role in the safety of the laboratory and effectively protects the normal progress of classroom teaching and scientific research ${ }^{[9]}$.

The security access system of foreign universities such as American university laboratories has been fully implemented for a long time. Before entering the laboratory, all personnel must read the laboratory's chemicals and equipment information. After passing the assessment, laboratory personnel must wear safety protection equipment to enter the laboratory or research ${ }^{[10-}$ 13].

"Corresponding author: Ying Chengjing; Email: anjibu_yingcj@hatram.com 
Some Chinese universities have also borrowed some forms from foreign universities, but their implementation is not ideal. Due to the large number of students in our country, or the complicated process has caused students to resist emotions, or lack of safety awareness and lack of humanistic management and other reasons. The important thing to note is that the American laboratory safety education manuals generally only explain how to respond to emergencies, how to ask for help and self-help and how to notify peers to evacuate and evacuate. Domestic safety education often emphasizes the serious consequences of accidents caused by incorrect operation and bears multiple accident responsibilities. Finally, some safety self-rescue measures may be introduced. Safety education at home and abroad gives people different feelings. These subtle differences often remind people to reflect on the purpose of safety education and how to effectively learn from the form and content of foreign safety education according to the actual situation of domestic laboratories ${ }^{[14]}$.

\section{Characteristics of safety accidents in college laboratories}

\subsection{Types and characteristics of accidents}

This research divides university laboratory safety accidents into five categories, fire accidents(A1), explosion accidents(A2), mechanical injury accidents(A3), toxic and hazardous substance injury accidents(A4), and biological safety accidents(A5).

In order to more systematically analyze the types and situations of laboratory safety accidents in Chinese universities. Figure 1 shows the typical laboratory safety accidents reported in Chinese universities from 2005 to 2017 through search and statistics. In 50 laboratory accidents, 8 people were killed and 81 people were injured, including 28 people were poisoned.

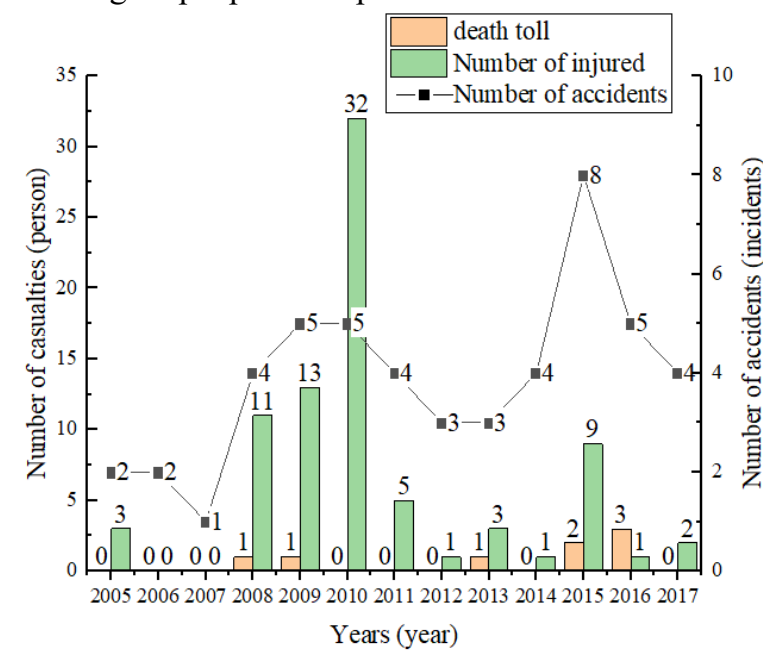

Figure 1 Statistics of casualties from 2005 to 2017

The summary shown in Figure 2 found that the 50 typical laboratory safety accidents were mainly fires, explosions, toxic and hazardous substance injuries, biological infections and other safety accidents.
The statistical results show that among various accidents, there are more fire accidents and explosion accidents. The number of explosion accidents was the most, with the total of 24 , causing the most casualties, accounting for $43.2 \%$ and $75.0 \%$ of the total number of accidents and deaths respectively.

The main types of safety accidents in college laboratories are fire, explosion and toxic and hazardous substance injury accidents. Because laboratories use more flammable, explosive and toxic chemicals and some experiments need to be carried out under special conditions, such as high temperature, high pressure, Ultra low temperature etc. If the laboratory rules and regulations and chemical characteristics are not strictly followed, or if there is slight negligence, fire, explosion, leakage and poisoning may occur.
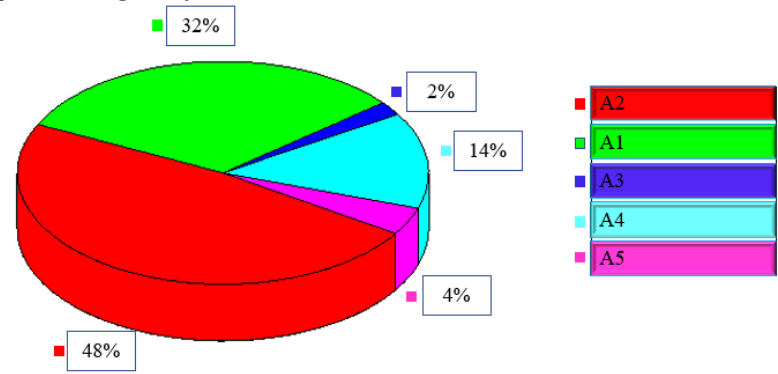

Figure 2 Statistics of accident types from 2005 to 2017

\subsection{Causes of safety accidents in college laboratories}

Table 1 Classification of accident causes

\begin{tabular}{|c|c|c|}
\hline NO. & Direct causes & Indirect causes \\
\hline A1 & $\begin{array}{l}\text { Forgot to turn off the } \\
\text { power } \\
\text { Unsafe operation } \\
\text { Throw cigarette butts } \\
\text { at will. etc }\end{array}$ & $\begin{array}{c}\text { Line aging } \\
\text { Overload operation. } \\
\text { etc }\end{array}$ \\
\hline $\mathrm{A} 2$ & $\begin{array}{l}\text { Violation of operating } \\
\text { procedures } \\
\text { Burning of flammable } \\
\text { items. etc }\end{array}$ & $\begin{array}{c}\text { Device not updated } \\
\text { in time } \\
\text { Leakage of } \\
\text { flammable and } \\
\text { explosive materials. } \\
\text { etc }\end{array}$ \\
\hline A3 & $\begin{array}{l}\text { Improper operation } \\
\text { Protection measures } \\
\text { are not in place } \\
\text { Violation of operating } \\
\text { procedures } \\
\text { Aging of equipment } \\
\text { and facilities. etc }\end{array}$ & $\begin{array}{l}\text { Equipment failures } \\
\text { or defects } \\
\text { Insufficient technical } \\
\text { procedures. etc }\end{array}$ \\
\hline A4 & $\begin{array}{l}\text { Violation of operating } \\
\text { procedures } \\
\text { No protective gear } \\
\text { Poisoning by accident } \\
\text { Lack of management. } \\
\text { etc }\end{array}$ & $\begin{array}{l}\text { Aging of equipment } \\
\text { and facilities } \\
\text { Leakage of toxic } \\
\text { substances or } \\
\text { accumulation of } \\
\text { toxic gas. etc }\end{array}$ \\
\hline A5 & $\begin{array}{l}\text { Violation of operating } \\
\text { procedures } \\
\text { Improper operation } \\
\text { Insufficient protection } \\
\text { measures. etc }\end{array}$ & $\begin{array}{l}\text { Complex operating } \\
\text { procedures } \\
\text { Chaos in step } \\
\text { management. etc }\end{array}$ \\
\hline
\end{tabular}


Table 1 shows that the analysis of the causes of safety accidents in college laboratories is summarized as direct causes and indirect causes, which are analyzed from the three aspects of equipment, personnel and management.

\section{Analysis of the weight of the cause of the accident}

This study uses the Analytic Hierarchy Process(AHP) to calculate the weight of each index that affects university laboratories. AHP is a method of subjective analysis of weights. It was proposed by Professor Saaty in the 1970s and has been widely used in the evaluation of indicator systems.

According to the previous statistical classification of the causes of laboratory safety accidents, the following factors affecting laboratory safety are summarized and listed, (1)Personnel's unfamiliarity, operating errors and contempt of each link in the experiment process. (2)The running time of the equipment is too long, the failure occurs and the load is reached. (3)Lack of supervision and training of personnel in management and lack of management and inspection of equipment. (4)For the existing technologies that are more widely used, the technology is immature, the conditions are harsh and the difficulty is relatively high. (5)The environment is not conducive to stable experiments and accidents.

These factors are used as laboratory safety accident evaluation indicators and recorded as indicators, personnel(C1), equipment(C2), management(C3), technology $(\mathrm{C} 4)$, environment(C5). According to the scoring rules specified by the analytic hierarchy process, qualitative judgments are expressed in a quantitative manner. The scoring rules are shown in Table 2 and the form of the judgment matrix is shown in Table 3 .

Table 2 AHP Pairwise Comparison Importance Scoring Rule

\begin{tabular}{ccc}
\hline NO & Relative importance & $a_{i \mathrm{j}}$ \\
\hline 1 & $i$ and $j$ are equally important & 1 \\
2 & $i$ is slightly more important than $j$ & 3 \\
3 & $i$ is obviously more important than $j$ & 5 \\
4 & $i$ is stronger than $j$ & 7 \\
5 & $i$ is extremely important than $j$ & 9 \\
6 & $i$ is slightly less important than $j$ & $1 / 3$ \\
7 & $i$ is slightly more important than $j$ & $1 / 5$ \\
8 & $i$ is slightly more important than $j$ & $1 / 7$ \\
9 & $i$ is slightly more important than $j$ & $1 / 9$ \\
\hline
\end{tabular}

Note: $C_{i j}=\{2,4,6,8,1 / 2,1 / 4,1 / 6,1 / 8\}$ means that the relative importance is between $=\{1,3,5,7,9,1 / 3$, $1 / 5,1 / 7,1 / 9\}$ in the middle.

Table 3 Judgment matrix of the importance of AHP

\begin{tabular}{ccccc}
\hline $\boldsymbol{C}$ & $\mathrm{C}_{1}$ & $\mathrm{C}_{2}$ & $\cdots$ & $\mathrm{C}_{\mathrm{i}}$ \\
\hline $\mathrm{C}_{1}$ & $\mathrm{C}_{11}$ & $\mathrm{C}_{22}$ & $\cdots$ & $\mathrm{C}_{1 \mathrm{i}}$ \\
$\mathrm{C}_{2}$ & $\mathrm{C}_{21}$ & $\mathrm{C}_{22}$ & $\cdots$ & $\mathrm{C}_{2 \mathrm{i}}$ \\
$\vdots$ & $\vdots$ & $\vdots$ & $\vdots$ & $\vdots$ \\
$\mathrm{C}_{\mathrm{i}}$ & $\mathrm{C}_{\mathrm{i} 1}$ & $\mathrm{C}_{\mathrm{i} 2}$ & $\cdots$ & $\mathrm{C}_{\mathrm{ii}}$ \\
\hline
\end{tabular}

The pairwise comparison matrix is performed and the values are assigned according to their importance to obtain the judgment matrix. The judgment matrix is as follows.

$$
C=\left(\begin{array}{ccccc}
1 & 4 & 1 / 3 & 7 & 6 \\
1 / 4 & 1 & 1 / 5 & 3 & 5 \\
3 & 5 & 1 & 8 & 8 \\
1 / 7 & 1 / 3 & 1 / 8 & 1 & 2 \\
1 / 6 & 1 / 5 & 1 / 8 & 1 / 2 & 1
\end{array}\right)
$$

This study uses the sum-product method to calculate its maximum characteristic root $\lambda_{\max }$.

(1) The elements of the judgment matrix $\boldsymbol{C}$ are normalized by column to obtain the matrix $\boldsymbol{B}=\left(b_{i j}\right)_{n \times n}$.

$$
b_{i j}=\frac{a_{i j}}{\sum_{i=1}^{n} a_{i j}}, \quad(i, j=1,2, \cdots, n)
$$

(2) Add the elements in matrix $\boldsymbol{B}$ row by row to get the vector $\boldsymbol{C}=\left(c_{1}, c_{2}, \ldots, c_{n}\right)^{\mathrm{T}}$.

$$
c_{i}=\sum_{j=1}^{n} b_{i j},(i, j=1,2, \cdots n)
$$

(3) Normalize the vector $\boldsymbol{C}$ to obtain the feature vector $\boldsymbol{W}=\left(w_{1}, w_{2}, \ldots, w_{n}\right)^{\mathrm{T}}$.

$$
w_{i}=\frac{c_{i}}{\sum_{k=1}^{n} c_{k}}, \quad(i=1,2, \cdots, n)
$$

The largest characteristic root $\lambda_{\max }$.

$$
\lambda_{\max }=\frac{1}{n} \sum_{i=1}^{n} \frac{(A W) i}{w i}
$$

This research uses Excel to process the data and the results are shown in Table 4.

Table 4 Data processing results of AHP

\begin{tabular}{ccccccc}
\hline $\boldsymbol{B}$ & $\mathrm{C} 1$ & $\mathrm{C} 2$ & $\mathrm{C} 3$ & $\mathrm{C} 4$ & $\mathrm{C} 5$ & $\omega$ \\
\hline C1 & 0.219 & 0.380 & 0.187 & 0.359 & 0.273 & 0.284 \\
$\mathrm{C} 2$ & 0.055 & 0.095 & 0.112 & 0.154 & 0.227 & 0.129 \\
$\mathrm{C} 3$ & 0.658 & 0.475 & 0.561 & 0.410 & 0.364 & 0.493 \\
C4 & 0.031 & 0.032 & 0.070 & 0.051 & 0.091 & 0.055 \\
C5 & 0.037 & 0.019 & 0.070 & 0.026 & 0.045 & 0.039 \\
Sum & 1.000 & 1.000 & 1.000 & 1.000 & 1.000 & 1.000 \\
\hline
\end{tabular}

(4) Consistency check.

$$
C R=C I / R I
$$

In the formula, $C R$ is the random consistency ratio of the judgment matrix.

$\mathrm{CI}$ is the consistency index of the judgment matrix; it can be obtained by the following formula.

$$
C I=\frac{1}{m-1}\left(\lambda_{\max }-m\right)
$$

$R I$ is the average random consistency index of the judgment matrix, which can be obtained by referring to Table 5. 
Table 5 Consistency index values of AHP

\begin{tabular}{|c|c|c|c|c|c|}
\hline $\begin{array}{c}\text { Matrix } \\
\text { order }\end{array}$ & 1 & 2 & 3 & 4 & 5 \\
\hline$R I$ & 0.00 & 0.00 & 0.58 & 0.90 & 1.12 \\
\hline 6 & 7 & 8 & 9 & 10 & 11 \\
\hline 1.24 & 1.32 & 1.41 & 1.45 & 1.49 & 1.51 \\
\hline
\end{tabular}

When $C R>0.1$, the consistency of the judgment matrix is considered to be satisfactory, indicating that the weight distribution is reasonable, if $C R>0.1$ the weight distribution of the judgment matrix needs to be adjusted until the consistency is satisfactory. Therefore, $C I=-0.147$, $C R=-0.132$.

The data in Table 3 shows that the order of the weight coefficients of accident factors in the laboratory is $\mathrm{C} 3>\mathrm{C} 1>\mathrm{C} 2>\mathrm{C} 4>\mathrm{C} 5$. This is of great significance to how to focus on the management of laboratory safety work in the future.

\section{Conclusion}

(1) This research briefly analyzes the safety management system of domestic and foreign university laboratories and related laws, regulations and standards and analyzes the types and characteristics of accidents and the causes of accidents through statistics of 50 college laboratory accidents in recent years. The main types of accidents are fire, explosion and toxic and hazardous substance injury accidents.

(2) Based on the analysis of the weight of the cause of the accident based on the analytic hierarchy process, the results of laboratory safety management, personnel operation, equipment defects, immature technology and environmental conditions gradually weakened.

\section{Acknowledgements:}

Sponsored by National Science Foundation of China (51604174; 51706122) , Shanghai Rising-Star Program (20QB1401000), the Natural Science Foundation of Shanghai (19ZR1411500), the Science \& Technology Foundation of Guizhou Province ([2020]4Y055). "Chen Guang ” project supported by Shanghai Municipal Education Commission and Shanghai Education Development Foundation (17CG60)

\section{References}

1. Xiaoyan. Wang, Chinese Journal of Chemical Education 42, 113 (2021)

2. Haifeng. Liu, Hui. Zeng, Yizhen. Wang, Rui. Li, Rui. Lin, Guobin. Li, Guangzhou Chemical Industry 49, 200 (2021)

3. Longshuai. Hao, Mengdi. Liu, Yingyuan. Zhang, Guangdong Chemical Industry 48, 224 (2021)

4. Yue. Qi, Liu. He, Ziyuan. Xia, Experimental Technology and Management 38, 276 (2021)

5. Guojie. Ma, Experimental Technology and Management 37, 282 (2020)
6. Liyan. Liu, Guangling. Du, Hongxin. Zhang, Haichen. Lian, Jie. Bai, Yanmei. Han, Research and Exploration in Laboratory 38, 282 (2019)

7. Shenghua. Chang, Lijun. Gu, Cheng. Zhang, Shujuan. Wu, Fujiang. Hou, Experimental Technology and Management 36, 175 (2019)

8. Yuang. Xiao, Mou. Zhang, Zhaoliang. Wu, Research and Exploration in Laboratory 38, 286 (2019)

9. Wuyi. Li, Dafeng. Gu, Fang. Hu, Experimental Technology and Management 25, 10 (2008)

10. Yuhui. Liu, Dong. Xiang, Shaocai. Chen, Research and Exploration in Laboratory 30, 181 (2011)

11. Huidong. Qiu, Guang. Li, Wei. Wang, Yanhui. Long, Experimental Technology and Management 31, 203 (2014)

12. Junmin. Gao, Fangying. Ji, Yuangyuan. Liu, Tao. Wang, Ronghuan. Yuan, Qing. Lin, Experimental Technology and Management 31, 230 (2014)

13. Shi. Peng, Xiaoxing. Xing, Liangli. Wu, Research and Exploration in Laboratory 28, 151 (2009)

14. Hui. Ruan, Xiaohui. Xiang, Wuyi. Li, Experimental Technology and Management 26, 4 (2009) 